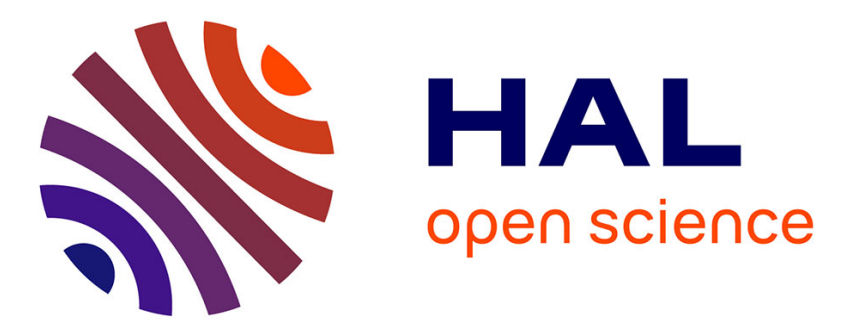

\title{
Textural images analysis of pasta protein networks to determine influence of technological processes
}

Anthony Fardet, P.M. Baldwin, Dominique Bertrand, B. Bouchet, D.J. Gallan, J.L. Barry

\section{To cite this version:}

Anthony Fardet, P.M. Baldwin, Dominique Bertrand, B. Bouchet, D.J. Gallan, et al.. Textural images analysis of pasta protein networks to determine influence of technological processes. Cereal Chemistry, 1998, 75 (4), pp.699-704. hal-02692838

\section{HAL Id: hal-02692838 \\ https://hal.inrae.fr/hal-02692838}

Submitted on 1 Jun 2020

HAL is a multi-disciplinary open access archive for the deposit and dissemination of scientific research documents, whether they are published or not. The documents may come from teaching and research institutions in France or abroad, or from public or private research centers.
L'archive ouverte pluridisciplinaire HAL, est destinée au dépôt et à la diffusion de documents scientifiques de niveau recherche, publiés ou non, émanant des établissements d'enseignement et de recherche français ou étrangers, des laboratoires publics ou privés.

\section{(c)(2)}

Distributed under a Creative Commons CCO - Public Domain Dedication| 4.0 International 


\title{
Textural Images Analysis of Pasta Protein Networks to Determine Influence of Technological Processes
}

\author{
A. Fardet, ${ }^{1}$ P. M. Baldwin, ${ }^{2}$ D. Bertrand,${ }^{3}$ B. Bouchet, ${ }^{2}$ D. J. Gallant, ${ }^{2}$ and J.-L. Barry ${ }^{1,4}$
}

\section{ABSTRACT}

Cereal Chem. 75(5):699-704

The structure of pasta is largely governed by the presence of a structured protein network. This work analyzed the protein network textures of various cooked pasta products through textural image analysis. Six different pasta types were investigated: reference pasta made from durum semolina; pasta enriched with gluten proteins from soft wheat flour at 10 and $20 \%$; autoclaved pasta; soft wheat flour pasta; and pasta made from reconstituted flour fractions. Pasta samples were sectioned, and each crosssection consisted of three distinct zones (central, intermediate, and external) based on the state of swelling of starch granules for each pasta product.
Digital images of the protein network in each zone were acquired using confocal laser scanning microscopy. Textural image analysis was then performed. Similarities and differences in protein network texture were assessed by principal component, stepwise discriminant, and variance analyses. With the exception of autoclaved pasta, protein network structure differed greatly with the position in the pasta. Furthermore the effect of technological treatments was greatly influenced by the position in pasta. The most significant differences in protein network structure were obtained with the autoclaved and $20 \%$ protein-enriched samples.
Food products cannot only be characterized by chemical composition but also by three-dimensional organization at three distinct levels: molecular, microscopic, and macroscopic. The molecular level governs the steric hindrance and interactions of the food macromolecules. At the microscopic level, the structures and interactions of larger components such as protein, starch, matrices, and polymers play a critical role in food texture. At this level, microscopic methods (e.g., optical, scanning electron, and confocal laser microscopy) allow the description of the organization of the different components. Such description is facilitated by appropriate staining and by three-dimensional reconstruction. The macroscopic level is characterized by the shape of the isolated food particles and by the overall texture of foodstuffs, both of which largely depend on the three-dimensional arrangement of food components (e.g., three-dimensional polymeric networks). The recent development of confocal laser scanning microscopy (CLSM), with its ability to optically section samples, allows visualization of the three-dimensional organization of macromolecular food networks inside hydrated food matrices without impairing the physical structure. Such a technique is of particular interest for pasta in which partly swelled starch granules are encapsulated by a protein network. This network is responsible for the slow degradation of starch in pasta, due to its limiting effect on the accessibility of starch to $\alpha$-amylases. Unlike other microscopic techniques, such as conventional optic and scanning electron microscopy, CLSM allows characterization of the geometry of the protein network both in single planes and in a three-dimensional space. The images resulting from CLSM may be digitized and stored. In this way, a great number of images can be rapidly acquired and processed.

In cereal-based products, a good understanding of the three levels of food organization is essential for the improvement of food product formulation. For example, the addition of surfactants to flour alters the textural appearance of the bread crumb (which is representative of the macroscopic level) (Pomeranz et al 1992). Such technological modifications can be characterized by certain rheological measurements (Keetels et al 1996), but may also be studied by artificial vision associated with image analysis (Bertrand et al

\footnotetext{
${ }^{1}$ Institut National de la Recherche Agronomique, Laboratoire des Fonctions digestives et de Nutrition Humaine Rue de la Géraudière, B.P.71627, 44316 Nantes Cédex 03, France.

2 INRA, Laboratoire de Biochimie et Technologie des Glucides

${ }^{3}$ INRA, Laboratoire de Physique et Technologie des Végétaux

${ }^{4}$ Corresponding author. E-mail: barry@nantes.inra.fr Phone: +33 (0) 2024067 5020. Fax: +33 (0) 20240675012 .
}

Publication no. C-1998-0806-04R.

(C) 1998 American Association of Cereal Chemists, Inc.
1992). Microscopic images often do not contain well-defined isolated objects, and it is easier to interpret them as a repetitive arrangement of basic patterns, called an image texture (Smolarz et al 1989). In the domain of artificial vision, many mathematical methods have been developed for the extraction of textural features from images (Haralick et al 1973, Galloway 1975). Such methods make it possible to emphasize the differences in the textural appearance of food products as a function of the applied technological treatments or of the origin of the raw materials (Fains et al 1997). In pasta particularly, it is possible to vary the choice of the ingredients and technological parameters involved in the manufacture to obtain a wide range of pasta products. However, currently it is difficult to rapidly characterize the subsequent modifications of the protein network texture. The present study aimed to apply image texture analysis for the characterization of the influence of various pasta processing parameters. Collections of images were acquired using CLSM. By analyzing the appearance of the protein network structure after cooking, the nature of the raw material (flour vs. semolina), the level of protein-enrichment, the fractionation-reconstruction procedure of flour, and the thermal treatments (normal cooking vs. autoclaving) were investigated. Fibers play an important role in the texture of cereal based products such as bread (Izydorczyk and Biliaderis 1995). It was therefore also interesting to study the influence of the insoluble fiber fraction on the structure of the protein network in pasta. In pasta, the degree of starch swelling increases from the center to the outer part of samples (Pagani et al 1986, Cunin et al 1995). Thus, the relationship between the texture of the protein network and the physical location in the pasta was also investigated.

\section{MATERIALS AND METHODS}

\section{Sample Preparation}

Wheat pastas were prepared from durum wheat semolina (3SE quality, $84.8 \%$ dry matter, $74.7 \%$ starch, $11.8 \%$ protein) (Semoulerie de Caen, France) and soft wheat flour (84.4\% dry matter, $72.2 \%$ starch, $11.0 \%$ protein) (Minoterie du Feuillou, Boussay, France). Durum semolina and soft flour were extruded at $40^{\circ} \mathrm{C}$ as spaghetti (1.5 and $1.2 \mathrm{~mm}$ diameters, respectively). The spaghetti was then dried for $17 \mathrm{hr}$ at $55^{\circ} \mathrm{C}$. During drying, the relative humidity was decreased from 92 to $72 \%$ rh to obtain a final moisture content of $13 \%$. The processed products were referred as $\mathbf{S P}_{\text {ref }}$ (for spaghetti made from durum wheat) and $\mathbf{S P}_{\mathrm{fl}}$ (for spaghetti made from native soft wheat flour). $S P_{\text {ref }}$ was considered the reference pasta for comparison with other samples.

All flours naturally contain a certain amount of insoluble fibers. A reconstructed flour was prepared to create a sample of insoluble 
fiber-free flour. Initially, gluten, starch, soluble matter, and insoluble fiber fractions were prepared according to the procedure developed by Popineau et al (1985). The insoluble fiber fraction was removed, and flour was reconstituted by mixing the remaining fractions in the initial proportions. Reconstructed flour $\left(\mathrm{SP}_{\mathrm{rec}}\right)$ was extruded at $40^{\circ} \mathrm{C}$ as spaghetti (1.2 mm diameter), dried for $17 \mathrm{hr}$ at $55^{\circ} \mathrm{C}$.

Protein-enriched pasta was made from durum semolina enriched with commercial gluten proteins from wheat flour (Gluten Supra Vital L, Ref. 617177, Roquette, France). The gluten proteins were added to achieve total protein contents 10 and $20 \%$ higher than the original semolina protein content, and the enriched semolinas were processed to make pasta as described for $\mathrm{SP}_{\text {ref. }}$ Protein-enriched pasta (10 and $20 \%$ ) was extruded at $40^{\circ} \mathrm{C}$ as spaghetti $(1.7$ and $1.9 \mathrm{~mm}$ diameter, respectively). These pasta products were referred to as samples $\mathrm{SP}_{+10}$ and $\mathrm{SP}_{+20}$.

Each pasta product was then cooked for an optimum cooking time determined according to the French national standard (AFNOR 1989 ) in which $10 \mathrm{~g}$ of spaghetti (5-cm strands) are boiled in $300 \mathrm{~mL}$ of $0.7 \%$ salted spring water (Evian). The optimal cooking time corresponds to the occurrance of complete gelatinization of the starch and the disappearance of the white central core of the spaghetti. After cooking and just before sample preparation for image acquisition, the spaghetti strands were soaked for 3-5 $\mathrm{min}$ in distilled water at ambient temperature.

Pasta made from durum semolina were also cooked for $2 \mathrm{~min}$ in $0.7 \%$ salted boiling spring water, and then sterilized at $115^{\circ} \mathrm{C}$ in an autoclave for $40 \mathrm{~min}$. This sample was referred as $\mathrm{SP}_{\mathrm{A} 40}$.

The six samples created by different technological treatments were $\mathrm{SP}_{\text {ref, }}, \mathrm{SP}_{\text {fir }}, \mathrm{SP}_{+10}, \mathrm{SP}_{+20}, \mathrm{SP}_{\text {rec}}$, and $\mathrm{SP}_{\mathrm{A} 40 \text {. }}$

\section{CLSM and Image Acquisition}

CLSM (Zeiss LSM 410, Carl Zeiss, Germany) was used for examining the overall organization and three-dimensional structure of the protein network of pasta inside the cooked samples. For each pasta sample, two or three sections of different spaghetti strands were prepared using a cryotome ( $20 \mu \mathrm{m}$ section thickness). The sections were then dried $16 \mathrm{hr}$ in an oven at $50^{\circ} \mathrm{C}$ and then stained for $10 \mathrm{~min}$ in a $0.01 \%(\mathrm{w} / \mathrm{v})$ fuchsin acid solution diluted in acetic acid $1 \%(v / v)$. Sections were rinsed for $1 \mathrm{hr}$ in distilled water and mounted in distilled water onto flat glass slides. A coverslip was added, and the preparation was sealed with nail varnish to prevent drying.

Samples were examined in the epifluorescence mode of the microscope. Samples were excited by a green laser beam at $543 \mathrm{~nm}$ and the emitted light was selected by a long-pass filter $(>570 \mathrm{~nm})$. The laser beam focused on a plane $\approx 1 \mu \mathrm{m}$ thick inside the sample. Images were acquired with CLSM microscope parameters of pinhole (15), objective (40), and zoom (2).

CLSM images were digitized in the form of pixel arrays of 512 rows by 512 columns. The gray levels were coded on 8 bits, giving an intensity scale from 0 (black) to 255 (white). Each image corresponded to a sample area of $162 \times 162 \mu \mathrm{m}$.

To study the change of the protein network as a function of the location in the sample, microscopic images were acquired at three different zones in the spaghetti: external $(\mathrm{E})$, intermediate (I), and central (C). As the diameter of the cross sections of spaghetti dif-

TABLE I

Number of Images Acquired for Each Treatment

\begin{tabular}{lccc}
\hline & \multicolumn{3}{c}{ Zones } \\
\cline { 2 - 4 } & Central & Intermediate & Exterior \\
\hline Reference & 10 & 21 & 20 \\
Protein enriched at 10\% & 20 & 31 & 26 \\
Protein enriched at 20\% & 15 & 32 & 27 \\
Autoclaved & 10 & 20 & 20 \\
Native flour & 6 & 24 & 15 \\
Reconstructed flour & 5 & 26 & 13 \\
\hline
\end{tabular}

fered according to the applied technological treatment, it was impossible to acquire the same number of different images for each zone and each sample. Five to 30 images (from two or three pasta strands) were randomly acquired in each zone for each of the six technologically different pasta samples (Table I). Thus, 341 images were collected and stored on a computer for subsequent mathematical treatment.

\section{Image Processing}

Image processing consisted of two basic steps. In the first step, extraction of texture features, wherein numerical values, called texture features were assessed from the digitized images. These values are theoretically representative of the textural appearance of the images. In the second step, the images were compared by means of multidimensional analyses such as principal component analysis (PCA) and stepwise discriminant analysis (SDA).

Extraction of texture features from images. The texture features were assessed by using a technique called the gray level run length method (Galloway 1975). A digitized image can be seen as a matrix $\mathrm{X}_{(\mathrm{i}, \mathrm{j})}$ where $i$ is the index of the row, and $j$ is the index of the column. A value of this matrix $\mathrm{x}_{(\mathrm{i}, \mathrm{j})}$ represents the gray level intensity at location $(i, j)$. A run length in a given direction represents the number of consecutive pixels with the same gray-level values. For a given gray level intensity and a given direction in the image, it is possible to assess the distribution of the run lengths.

For a digitized image, the run length distribution associated to a given direction can be gathered in a matrix $R_{(g, 1)}$, where $a$ is the total possible number of gray level intensities (256 for pixels coded with 8 bits), and $b$ is the maximum possible run length of the image (e.g., $b=512$ for an image of $512 \times 512$ pixels). A value $\mathrm{r}_{(\mathrm{g}, \mathrm{l})}$ of this matrix gives the number of run lengths equal to $l$, for the gray level value $g$, that have been encountered in the whole image, for a given direction. There are as many matrices $\mathrm{R}$ as the number of studied directions. It is then possible to assess different numerical values that summarize the features of $\mathrm{R}$ (texture features). The precise way of calculating these features are described in Galloway (1975) and are not detailed here. However the significance of these features is described below.

Short run emphasis (sre): a high value relates to a greater number of short runs (i.e., an image with fine structure) in the direction studied; long run emphasis (Ire): a high value of this function relates to more long run lengths contained in the image and the image may be interpreted as having a coarser structure, in the direction studied; gray level distribution (gld): also known as gray level nonuniformity, indicates the distribution of gray levels in the image (when runs are equally distributed throughout the gray levels, this function takes on its lowest values); run length distribution (rld): also referred to as run length nonuniformity, where runs are equally distributed throughout the lengths, the function takes a low value (large runs contribute most significantly to this function); run percentage ( $r \%$ ): This function is the ratio of the total number of runs to the total number of possible runs if all runs had a run length of 1 (its lowest value is for images that are less grainy in the chosen direction).

These five parameters were defined for three directions at angles 0,45 , and $90^{\circ}$, which gave a total of 15 parameters for each image studied. The vector of these 15 parameters assessed from each image contained information about the textural appearance of the sample, making it possible to use multidimensional analyses such as PCA to emphasize the similarities between image textures. For this goal, the textural features were gathered into a matrix $F_{(i, j)}$ where $i$ represents an image and $j$ represents the texture feature of this image. F had dimensions of $341 \times 15$ (Table I).

Multidimensional analysis. To give an equal importance to each texture feature in PCA, the matrix F was normalized (i.e., each column was divided by its standard deviation). PCA was applied on the normalized matrix F (Jollife 1986, Sharaf et al 1986). PCA made it possible to draw similarity maps of the texture features. In 
such maps, each image was represented by a point. When two images had a similar textural appearance they were neighboring or superposed on the map.

PCA also allows the representation of the variables on correlation circles (Foucart 1982). In such a representation, the variables are plotted in a circle with a radius of 1 , which represents perfect correlation. Two variables that are close to the circumference and neighboring are highly positively correlated. If they are directly opposite on the circumference, they are highly negatively correlated. Variables far from the circumference are not representative of the two principle components under study.

Discriminant analysis. This was useful to identify the texture analysis parameters that were the most relevant for discrimination of images, depending on the location in the spaghetti (external, intermediate, central) and the technological treatment applied. To achieve this, stepwise discriminant analysis (SDA) (Romeder 1973) was applied on the matrix $\mathrm{F}$. The qualitative groups were defined either by the position in the spaghetti or by the technological treatments.

Image processing and discriminant analyses were performed with software written in $\mathrm{C}++$ language by the authors.

Variance analysis of texture features. Zones in the pasta products (Z) and technological treatments ( $\mathrm{T}$ ) were taken as factors for a two-way analysis of variance. The interaction $\mathrm{Z} \times \mathrm{T}$ was taken into account in the model. This data processing was performed on Splus software (Becker et al 1988).

\section{RESULTS AND DISCUSSION}

This study aimed to describe the texture of protein network in pasta products, depending on the location in the spaghetti cross section, and on the technological treatments applied. Initially, images of the reference pasta product $\left(\mathrm{SP}_{\text {ref }}\right)$ were acquired, and the dependence of texture on the location was studied. The effect of technological treatments was then investigated. The interaction between technological treatments and spatial organization of texture was evaluated by means of variance analyses.

\section{Textural Analysis of the Protein Network}

Typical CLSM images of sample $\mathrm{SP}_{\text {ref }}$ are shown Fig. 1 . In these images, the protein network appears as a white structure on a black background that mainly corresponds to the starchy fraction. The fuchsin acid staining technique then revealed essentially the protein fraction. Significant variations in the texture were apparent from the external to the central zones. This was related to the degree of swelling of starch granules which depends on the location in the pasta products (Cunin et al 1995), with the protein and the starch competing with each other for absorbable water (Eliasson 1983). During pasta cooking, the protein network limits water diffusion to the starch granules, which limits swelling in the central zone of pasta. On the basis of this knowledge, and our observations, we divided pasta cross-sections into three parts: external (E), intermediate (I) and central (C) zones. In the external region, the fine fibrils of the protein network were separated by large black areas. The intermediate and central zones, however, were more similar to one another, although the protein fibrils formed a coarser structure in the central zone than in the intermediate zone. The large and small starch granules were clearly visible as large and small black areas surrounded by the higher emission of the protein network. In the central zone, the dark areas were smaller than in the external zone.

After defining the zones, 5-32 images were acquired from each zone in each pasta product. Such a high number of similar images could not be efficiently and objectively compared by simple visual evaluation so it was necessary to apply rapid, nonsubjective characterization of image texture. This was achieved by the application of an image texture analysis technique, the gray level run length method, and by multidimensional analyses applied on the extracted texture features.

To appreciate the importance of the location on the texture of the reference pasta protein network, PCA was initially applied on the normalized data of the 15 assessed texture features. In this case, 51 CLSM images were included in the data matrix: 20 from the external zone, 21 from the intermediate zone, and 10 from central zone (Table I). In this PCA, the first and the second eigenvalues represented 91.3 and $7.6 \%$ of the total sum of the square, respec-

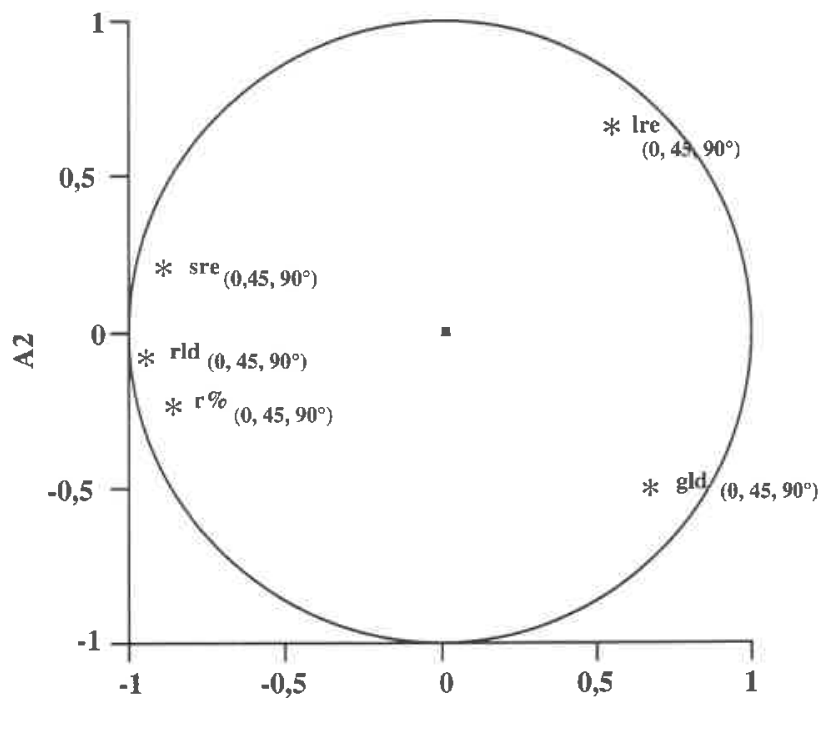

A1

Fig. 2. Correlation circle for the texture features. Five parameters for three directions at angles 0,45 , and $90^{\circ}$ : sre, short run emphasis; rld, run length distribution; $r \%$, run percentage; lre, long run emphasis; gld, gray level distribution. $\mathrm{A} 1=$ component $\mathrm{m}^{\circ} 1, \mathrm{~A} 2=$ component $\mathrm{m}^{\circ} 2$.
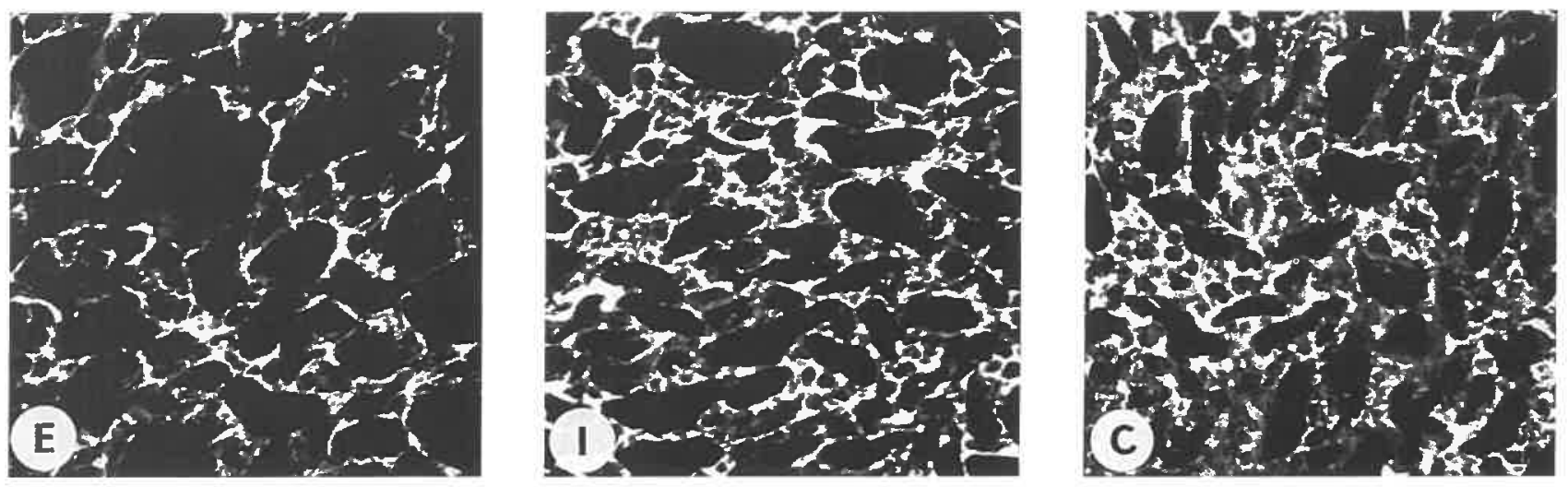

Fig. 1. Typical images (acquired by confocal laser scanning microscopy) of the reference pasta in the external (E), intermediate (I) and central (C) zones. $\mathrm{Bar}=25 \mu \mathrm{m}$. 
tively. The first component was highly representative of the data, and it seemed sufficient to analyze the significance of the two first components. The correlation circle of the textural features related to these components is shown in Fig. 2. The variable code is followed by the value of the angle $\left(0,45,90^{\circ}\right)$ that was used when assessing the textural features. With the exception of lre, the texture features were highly representative of the first component. Moreover, sre, rld and r\% were highly positively correlated with each other and negatively correlated with gld. The first component appeared to be descriptive of the degree of organization and the coarseness of the network. The texture features were independent of the angle applied for the texture analysis. For example, variables 1re0, 1re45 and lre 90 perfectly overlapped. This indicated that the image texture presented no preferential direction and was isotropic. This conclusion was not obvious from direct observation of the CLSM images.

The biplot of the observations is shown Fig. 3. For the sake of clarity, the scales of the two axes have been adjusted and are not identical. On this graph, each point summarizes the texture of a given image. Each image is coded by the location $(E, I, C)$. In general, the textural appearance of the images appeared to be clearly dependent on the location. Images from the external zone (E) presented positive values of the first PCA scores. In contrast, images from the central zone (C) were plotted in the negative part of the first axis. Images from the intermediary zone (I) were spread between images from zones $C$ and $E$, with $\approx 25 \%$ of images not distinct with images from zone $\mathrm{C}$ (Fig. 3). The range of scores observed with images from zone I was large, which showed that the texture of the intermediary zone was highly variable. Images from zone $\mathrm{E}$ were also split according to the second component. No obvious interpretation of this distribution could be found.

To identify the variables that were the most discriminating between the zones, SDA was applied on the texture features. In this case,

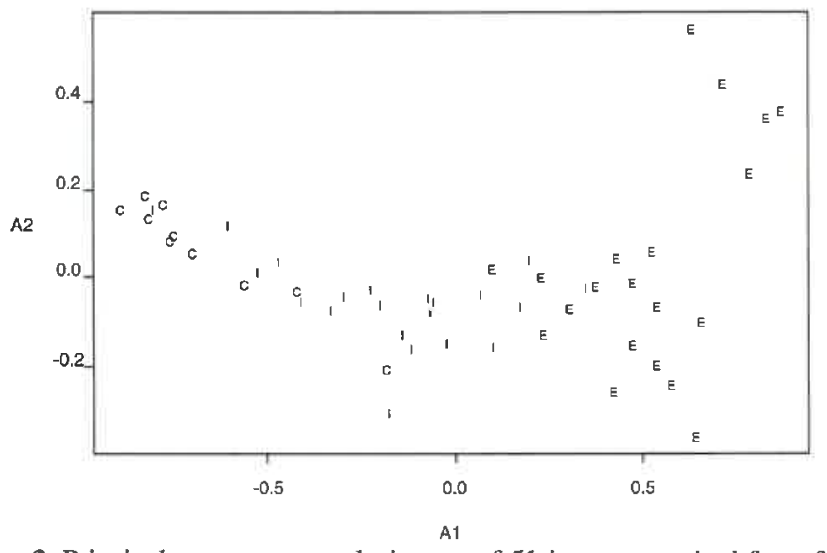

Fig. 3. Principal component analysis map of 51 images acquired for reference pasta in the external $(\mathrm{E})$, intermediate $(\mathrm{I})$ and central $(\mathrm{C})$ zones. $\mathrm{A} 1=$ component $\mathrm{m}^{\circ} 1, \mathrm{~A} 2=$ component $\mathrm{m}^{\circ} 2$.

TABLE II

Classification of Reference Pasta Images at Step 1 of Stepwise Discriminant Analysis

\begin{tabular}{lccc}
\hline Zone & Center & Intermediate & Exterior \\
\hline Center & 9 & 1 & 0 \\
Intermediate & 5 & 13 & 3 \\
Exterior & 0 & 0 & 20 \\
\hline
\end{tabular}

TABLE III

Variance Analysis of Treatments $\times$ Zone Interaction

\begin{tabular}{llrcrrr}
\hline Parameter Factors & df & Square Sum & Mean & $\boldsymbol{F}$ & $\boldsymbol{P}$ \\
\hline sre0 & Treatments & 5 & 126.9 & 25.38 & 95.17 & 0 \\
& Zone & 2 & 113.03 & 56.52 & 211.93 & 0 \\
& Interaction & 10 & 14.79 & 1.48 & 5.54 & 0 \\
& Residual error & 323 & 86.14 & 0.27 & $\cdots$ & $\cdots$ \\
\hline
\end{tabular}

the qualitative groups of SDA corresponded to the zones. A single parameter, $\mathrm{r} \% 0$, yielded a high percentage $(82.35 \%)$ of correct classification. When a second or a third variable was introduced into the model, no significant improvement was observed. The model with a single variable seemed to be the most appropriate. Table II shows the classification of the images given by SDA when using a single variable. In Table $\amalg$, the rows represent the actual zone and the columns represent the classification from the SDA. With one exception, the external and central zones were correctly identified. In contrast, images from the intermediary zone were often misclassified as being from the central or external zones.

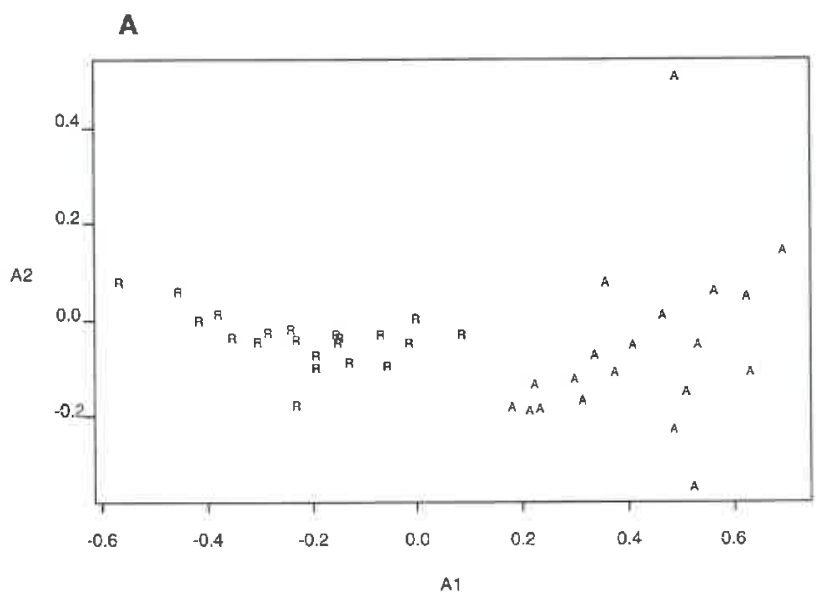

B
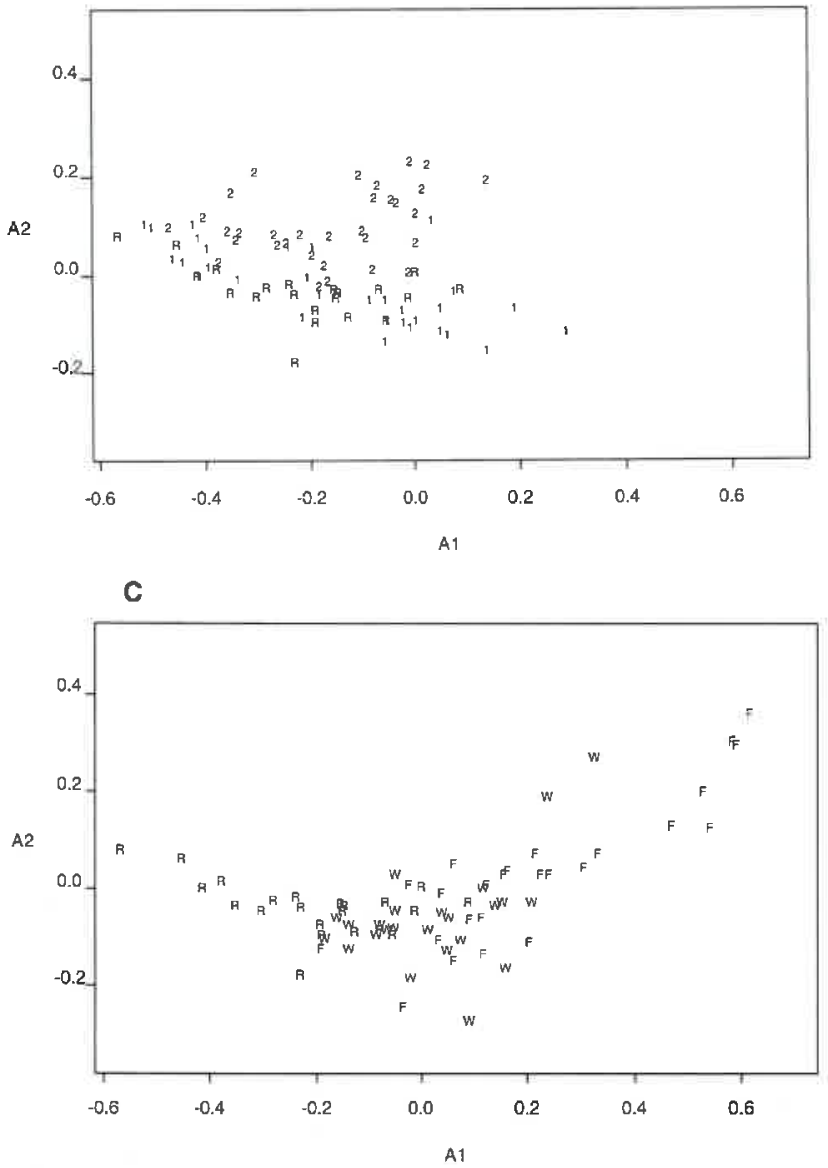

Fig. 4. Principal component analysis maps representing influence of cooking procedure (A), protein enrichment $(\mathbf{B})$, botanical origin and fractionation-reconstruction procedure of flour $(\mathbf{C})$. $\mathrm{R}=$ reference pasta; $\mathrm{A}=$ autoclaved pasta; 1 and 2 = protein enriched pastas; $W=$ pasta made from native flour; and $\mathrm{W}=$ pasta made from reconstructed flour. $\mathrm{A} 1$ = component $\mathrm{m}^{\circ} 1, \mathrm{~A} 2=$ component $\mathrm{m}^{\circ} 2$. 
From this study, we concluded that the textural appearance of the protein network was clearly dependent on the location in the spaghetti, especially in the external and central zones. Texture analyses and multidimensional data processing were thus able to objectively confirm our initial subjective visual interpretations.

\section{Influence of Technological Treatments}

Images of different zones of spaghetti produced by six technological treatments $\left(\mathrm{SP}_{\text {ref, }} \mathrm{SP}_{\text {flr }}, \mathrm{SP}_{\text {rec }}, \mathrm{SP}_{+10}, \mathrm{SP}_{+20}, \mathrm{SP}_{\mathrm{A} 40}\right.$ ) were acquired. Because significant variation in the image texture was observed according to the zones in the pasta, it was useful to study the respective effect of the zone (Z), the technological treatment (T) and the interaction $\mathrm{Z} \times \mathrm{T}$ by variance analysis (ANOVA). As the textures appeared to have no defined orientation, it was sufficient to study only the set of texture features associated with one angle $\left(0^{\circ}\right)$. ANOVA was independently applied on each texture feature (sre0, lre0, gld0, rld0, r\%0) for the 341 available images. In each case, the effect of $\mathrm{Z}, \mathrm{T}$, and $\mathrm{Z} \times \mathrm{T}$ were very significant, with associated probabilities close to 0 . For example, the results of the ANOVA for sre 0 is shown in Table III. The treatment $(\mathrm{T})$ played an important role with an $F$ value equal to 95.17 , but the effect of the zone was still higher ( $F$ value equal to 211.93 ). Therefore it could be concluded that the effect of the treatment differed according to the zone. The same conclusions were obtained from the other texture features.

To emphasize the effect of the treatments on the organization of the protein network, three SDA were independently applied on the images of each zone with the treatments as the qualitative groups. The effect of the treatment was evaluated by considering the number of images correctly classified. The percentage of correct classifications ranged from $64.29 \%$ for intermediary zone to $75.76 \%$ for central zone (Table IV). Whatever the considered zone, autoclaving treatment, $\mathbf{S P}_{\mathrm{A} 40 \text {, }}$, was the most clearly identified with only 0-2 confusions with other treatments. Images for other treatments were often wrongly classified. For example, images from pasta sample $\mathrm{SP}_{\text {ref }}$ were often wrongly classified as images from sample $\mathrm{SP}_{+1(0)}$ - The same was observed between images from samples $\mathrm{SP}_{+10}$ and $\mathrm{SP}_{+20}$. On the contrary, images from sample $\mathrm{SP}_{\text {ref }}$ were never identified as images from sample $\mathrm{SP}_{+20}$. Thus, the protein enrichment caused a progressive modification of the texture. The reconstructed flour $\left(\mathrm{SP}_{\mathrm{rec}}\right)$ was not well classified and often wrongly identified as $\mathrm{SP}_{\mathrm{fl}}$. The removal of insoluble fibers did not lead to a marked modification of the image texture. The image texture obtained with soft wheat was generally well discriminated from that obtained with durum semolina. The intermediary zone, which was larger in the spaghetti, was chosen for further study. A PCA was applied on the texture features of this zone. For the sake of clarity, the biplot of the first and second components were split into several graphs to emphasize the effect of cooking procedure, protein enrichment, botanical origin, and fractionation.

Figure 4A illustrates the effect of cooking (either the normal cooking procedure $\mathrm{R}$ or the autoclaving process $\mathrm{A}$ ). The method of cooking had a strong influence on the texture. All the images from sample $\mathbf{R}$ had negative scores on the first axis, contrary to images from sample A. This can be explained by excessive swelling of starch granules obtained after autoclaving, whatever the position in pasta. This is what occurs in the external zone of normally cooked pasta $R$.

Figure 4B illustrates the influence of protein enrichment. Images from samples $\mathrm{R}$ and $1\left(\mathrm{SP}_{+10}\right)$ were often overlapped, whereas $\approx 50 \%$ of images from sample $2\left(\mathrm{SP}_{+20}\right)$ were clearly distinct. This is in agreement with the results of the previous SDA. The influence of the botanical origin (soft vs. durum wheat) and of the fractionation are shown in Fig. 4C. Durum wheat gave slightly more heterogeneous image textures (as shown by the range of scores) than soft wheat (W). As for images from autoclaved pasta (A), images from fractionated flours $(F)$ were more representative of an external zone (Fig. 3) when compared with images from R or W (Fig. 4C).

\section{CONCLUSION}

Many technological processes are used to produce textured food products (e.g., foams, cereal product crumb, fibrous materials). It is often difficult to appreciate the modification of the appearance of the product as a function of the parameters of the process. When the number of samples is $\geq 20$, it is necessary to have an objective evaluation method. Image texture analysis has the advantage of being both rapid and systematic, and can be applied in many situations without large modifications of the data processing. The drawback of this approach is that the extracted texture features are not directly interpretable in terms of geometric organization. However, by applying chemometric multidimensional analyses, it is possible to obtain relevant information and interpret the data collection.

TABLE IV

Classification of Images ${ }^{a}$ According to Treatment and Zone

\begin{tabular}{|c|c|c|c|c|c|c|}
\hline & SP $P_{\text {ref }}$ & $S P_{+10}$ & $\mathrm{SP}_{+20}$ & $\mathbf{S P}_{\mathbf{A} 40}$ & $\mathbf{S P} \mathbf{P}_{\mathrm{fl}}$ & $\mathbf{S P}_{\text {rec }}$ \\
\hline \multicolumn{7}{|c|}{ Intermediate zone (step 3 of SDA) $64.29 \%$ correctly classified ${ }^{b}$} \\
\hline$S P_{\text {tef }}$ & 10 & 11 & 0 & 0 & 0 & 0 \\
\hline $\mathbf{S P}_{+10}$ & 11 & 15 & 3 & 2 & 0 & 0 \\
\hline $\mathrm{SP}_{+20}$ & 4 & 2 & 26 & 0 & 0 & 0 \\
\hline $\mathrm{SP}_{\mathrm{A} 40}$ & 0 & 0 & 0 & 18 & 0 & 2 \\
\hline $\mathrm{SP}_{\mathrm{fir}}$ & 2 & 1 & 0 & 0 & 15 & 6 \\
\hline $\mathrm{SP}_{\mathrm{rec}}$ & 0 & 1 & 0 & 1 & 9 & 15 \\
\hline \multicolumn{7}{|c|}{ Center zone (step 2 of SDA) $75.76 \%$ correctly classified } \\
\hline $\mathrm{SP}_{\text {ref }}$ & 6 & 3 & 0 & 0 & 1 & 0 \\
\hline$S_{+10}$ & 1 & 18 & 1 & 0 & 0 & 0 \\
\hline $\mathrm{SP}_{+20}$ & 0 & 4 & 11 & 0 & 0 & 0 \\
\hline $\mathrm{SP}_{\mathrm{A} 40}$ & 0 & 0 & 0 & 10 & 0 & 0 \\
\hline$S P_{\text {flr }}$ & 0 & 1 & 0 & 0 & 5 & 0 \\
\hline $\mathrm{SP}_{\text {rec }}$ & 2 & 0 & 0 & 0 & 3 & 0 \\
\hline \multicolumn{7}{|c|}{ Exterior zone (step 4 of SDA) $70.25 \%$ correctly classified } \\
\hline $\mathrm{SP}_{\text {ref }}$ & 13 & 3 & 0 & 0 & 2 & 2 \\
\hline $\mathbf{S P}_{+10}$ & 4 & 19 & 1 & 1 & 0 & 1 \\
\hline $\mathrm{SP}_{+20}$ & 2 & 7 & 17 & 1 & 0 & 0 \\
\hline $\mathrm{SP}_{\mathrm{A} 40}$ & 0 & 0 & 0 & 18 & 1 & 1 \\
\hline $\mathrm{SP}_{\mathrm{flr}}$ & 0 & 0 & 0 & 0 & 11 & 4 \\
\hline$S P_{\text {rec }}$ & 1 & 2 & 0 & 1 & 2 & 7 \\
\hline
\end{tabular}

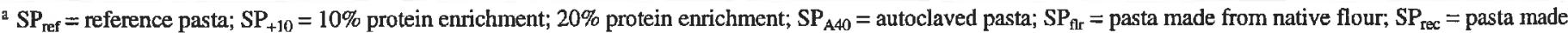
from reconstructed flour.

${ }^{b}$ Step of the stepwise discriminant analysis (SDA) chosen for maximum significantly correctly classified images. 
In the present study, it was possible to identify the factors that influence the texture of the protein network during the processing of pasta. The location in the pasta product played the most important role. Autoclaving produced a particular product texture, clearly different from that obtained by traditional cooking. The effect of protein enrichment was mainly visible at the $20 \%$ level. Surprisingly, the absence of insoluble fibers did not lead to a pronounced image textural effect. Our results demonstrated that image texture analysis provides an objective method to discriminate between different images. This allowed not only objective confirmation of our subjective visual textural interpretations, but also revealed information about the image sets that were visually less obvious such as the lack of an overall textural orientation.

From a nutritional point of view, it may be hypothesized that the large heterogeneity of the protein network observed will influence the enzymatic degradability of the starchy fraction. From the present study, it will be possible to identify typical microscopic textures. In further studies, it would be interesting to relate the observed textures with the kinetics of enzymatic starch hydrolysis

\section{LITERATURE CITED}

Becker, R. A., Chambers, J. M., and Wilks, A. R. 1988. The New S Language: A Programming Environment for Data Analysis and Graphics. Wadsworth and Brooks/Cole: Pacific Grove, CA.

Bertrand, D., Le Guernevé, C., Marion, D., Devaux, M. F., and Robert, P. 1992. Description of the textural appearance of bread crumb by video image analysis. Cereal Chem. 69:257-261.

Cunin, C., Handschin, S., Walther, P., and Escher, F. 1995. Structural changes of starch during cooking of durum wheat pasta. Lebensm. Wiss. Technol. 28:323-328.
Eliasson, A. C. 1983. Differential calorimetry studies on wheat-gluten mixtures. I. Effect of gluten on the gelatinisation of wheat starch. J. Cereal Sci. 1:199-205.

Fains, A., Bertrand, D., Baniel, A., and Popineau, Y. 1997. Stability and texture of protein foams: A study by video image analysis. Food Hydrocolloids 11:63-69.

Foucart, T. 1982. Analyse factorielle: Programmation sur microordinateur. Masson: Paris.

Galloway, M. M. 1975. Texture analysis using gray level run lengths. Comput. Graphics Image Process. 4:172-179.

Haralick, R. M., Shanmugan, K., and Dinstein, I. 1973. Textural features for image classification. IEEE. Trans. Sys. Man Cybern. 3:610-621.

Izydorczyk, M., and Biliaderis, C. G. 1995. Cereal arabinoxylans: Advances in structure and physicochemical properties. Carbohydr. Polym. 28:33-48.

Jollife, I. T. 1986. Principal Component Analysis. Springer-Verlag: New York.

Keetels, C. J. A. M., van Vliet, T., Jurgens, A., and Walstra, P. 1996. Effects of lipid surfactants on the structure and mechanics of concentrated starch gels and starch bread. J. Cereal Sci. 24:27-31.

Pagani, M. A., Gallant, D. J., Bouchet, B., and Resmini, P. 1986. Ultrastructure of cooked spaghetti. J. Food Structure 5:111-129.

Pomeranz, Y., Carvajal, M. J., Shrogen, M. D., Hoseney, R. C., and Finney, K. F. 1970. Wheat germ in breadmaking. II. Improving breadmaking properties by physical and chemical methods. Cereal Chem. 47:429.

Popineau, Y., Davin, A., and Godon, B. 1985. Wheat gluten extraction: Development of a small-scale extraction plant. Sci. Aliment. 5:133-153.

Romeder, J.-M. 1973. Méthodes et Programmes d'Analyse Discriminante. Dunod: Paris.

Sharaf, M. A., Illman, D. L., and Kowalski, B. R. 1986. Chemometrics. John Wiley and Sons: New York.

Smolarz, A., Van Hecke, E., and Bouvier, J.-M. 1989. Computerized image analysis and texture of extruded biscuits. J. Texture Stud. 20:223.

[Received February 26, 1998. Accepted June 19, 1998.] 